\title{
Por que é a nova arte de tão difícil compreensão? Um estudo sobre o primeiro modelo adorniano de sociologia musical (1931-1932)
}

\section{Why is the new art so hard to understand? A study on the first adornian model of musical sociology (1931-1932)}

\section{Lutti Mira}

Graduação em andamento em Filosofia (2014). Universidade de São Paulo - USP. Faculdade de Filosofia, Letras e Ciências Humanas, Departamento de Filosofia, São Paulo, SP - Brasil.

Resumo: Trata-se de analisar alguns dos ensaios sociológico-estéticos de Theodor Adorno do início dos anos 1930 na expectativa de estabelecer quais conceitos e diagnósticos balizaram seu primeiro modelo de sociologia musical. Segundo nosso argumento, os anos 1931-1932 marcariam uma inflexão determinante no curso da formulação de seu primeiro modelo sociológico, na medida em que as mesmas questões elaboradas na década anterior de 1920 seriam ali recolocadas em chave materialista. Esse movimento seria inspirado na articulação dos universos conceituais marxiano e weberiano promovida por Lukács em História e consciência de classe. Não obstante, tal inspiração, procuraremos salientar, não significou a adesão integral, por parte de Adorno, às teses desse livro de Lukács.

Palavras-chave: Adorno; Marxismo; Lukács; Teoria crítica; Sociologia da música.

\begin{abstract}
Our aim is to analyze some of Adorno's socio-aesthetical writings of the thirties in order to establish which concepts and diagnoses would ground his first model of musical sociology. According to our argument, the years of 1931-1932 delineated an important inflexion in the course of the formulation of his first sociological model, as far as in that period the same questions elaborated during the twenties would be replaced in a materialistic manner. This movement was inspired above all by the lukácsian articulation of the conceptual universes of Marxism and of weberianism, developed in History and class consciousness. Nevertheless, such inspiration, we argue, did not meant Adorno's integral adherence to the thesis present in Lukács book.
\end{abstract}

Keywords: Adorno; Marxism; Lukács; Critical theory; Musical sociology. 
Sabe-se que a década de 1930 aponta, da perspectiva de Adorno, para um período de transição que marca o início de sua recepção da obra de Marx e do marxismo em geral. ${ }^{1}$ Gostaríamos de seguir tal indicação, realizando uma análise de alguns textos sociológico-estéticos do período 1931-1932. Neste intuito, pretendemos expor a maneira pela qual as questões estéticas pensadas por Adorno durante a década de 1920 são repostas, logo ao início dos anos 30, em chave sociológica e materialista. Ao fazê-lo, salientamos desde já que não se trata de atestar esse processo como sendo uma prova do alinhamento de Adorno a um hegelo-marxismo de estirpe ortodoxa. ${ }^{2}$ Ao contrário, nosso intuito é estabelecer a maneira pela qual Adorno aquilatou o marxismo - sobretudo através da ótica lukácsiana - no momento em que tentava formular um diagnóstico sociológico acerca do então estágio social da música. Desse modo, ao delinear a primeira concepção de sociologia musical adorniana, é também nosso propósito indicar suas divergências em relação a certas correntes do marxismo. Num primeiro momento, analisaremos uma importante conferência de 1931, intitulada Por que é a nova arte de tão difícil compreensão? Sustentamos que a articulação materialista proposta por Adorno nesse ensaio repisa a articulação formulada por Lukács em História e consciência de classe entre os universos conceituais weberiano e marxiano, na medida em que Adorno conjuga a questão da forma mercadoria, de estirpe marxista, com os diagnósticos weberianos de racionalização e de autonomização das esferas de valor. Em segundo lugar, pretendemos explorar o primeiro texto de maior envergadura de Adorno, Sobre a situação social da música, de 1932, que marca a consolidação da abordagem sociológico-estética de Adorno.

Não seria exagero dizer que, em algum sentido, Adorno formou suas primeiras concepções estéticas como resposta aos problemas colocados pelo movimento expressionista alemão do início do século XX. Tal é, aliás, uma das empreitadas de Jorge de Almeida em seu livro Crítica dialética em Theodor Adorno. ${ }^{3}$ Para nossos propósitos, interessa tão somente ressaltar uma das questões com a qual Adorno teve de lidar durante os anos 20: a problemática da ruptura entre o eu e as formas. Se seguirmos o estudo de Almeida, temos que o expressionismo "é o primeiro momento da autoconsciência artística da impossibilidade do estilo". (ALMEIDA, 2007, p. 34). Em outras palavras, é característica marcante de tal movimento vanguardista que, em seu apreço pela expressão do eu individual em detrimento de formas pré-concebidas de organização do material artístico, a categoria englobante de estilo cesse de fornecer identidade à integridade da produção artística. Tal inflexão expressionista em favor da pureza de expressão livre de constrangimentos formais leva a uma ruptura de qualquer parâmetro estilístico que seja "capaz de servir como novo guia para a estruturação prévia da obra" (ALMEIDA, 2007, p. 84). Em suma, tem-se uma perda da Verbindlichkeit que antes era o próprio estofo da noção de Estilo. ${ }^{4}$ Donde surge

\footnotetext{
${ }^{1}$ Faço aqui referência à formulação de NOBRE, 1998, p. 61.

${ }^{2}$ Como quer, por exemplo, AGAMBEN, 2005.

${ }^{3}$ Sobre esse ponto, Carlo Petazzi, em seu livro Th. Wiesengrund Adorno: Linee di origine e di sviluppo del pensiero, chega mesmo a afirmar que o expressionismo exerceu uma influência decisiva em Adorno como linguagem, como forma expressiva e sobretudo como sensibilidade (cf. PETAZZI, 1975, p. 30ss).

${ }^{4}$ Como afirma Almeida: “(...) um conceito fundamental para esse debate [em torno do movimento expressionista]: Verbindlichkeit. A palavra, plena de significados, provém do verbo binden, que significa 'atar', 'vincular', mas também 'obrigar', 'comprometer'. Substantivado, designa a capacidade de criar laços e vínculos, impondo-os ao mesmo tempo como algo que constrange e obriga. Nesse sentido, os estilos históricos eram verbindlich porque expressavam os vínculos da esfera artística com outras esferas da sociedade. Ao mesmo tempo, eles também eram 'criadores de vínculos', pois reafirmavam esteticamente os valores de uma nação, cultura ou
} 
precisamente a questão da ruptura entre o eu - ou o artista - e as formas - ou os estilos que predispunham a organização das obras de arte. Como indica Max Paddison,

[Tal ruptura] se refere à desintegração dos gêneros tradicionais, tipos formais e esquemas e sua perda de significado enquanto normas compartilhadas, e sua inabilidade em satisfazer as demandas de expressão do período 'modernista'. A 'ruptura entre o eu e as formas' é a manifestação da alienação na música e um aspecto da fragmentação da vida moderna. Simultaneamente, todavia, a desintegração das formas serve para revelar sua historicidade, e a queda de um 'sistema referencial' como a tonalidade serve para revelar sua fundação aparentemente 'natural' como, na verdade, histórica - isto é, como uma 'segunda natureza' ligada a determinantes culturais particulares. (PADDISON, 1993, p. 31)

Paddison mobiliza assim as linhas mestras que a temática da ruptura entre o eu e as formas colocava para o pensamento estético de Adorno: de um lado, essa ruptura da Verbindlichkeit dos estilos é acompanhada de uma perda da compreensibilidade imediata das obras, que não mais se fundam no lastro comunitário que outrora sustentava as formas estéticas. ${ }^{5}$ Tal ruptura, vale notar, funciona para Adorno como a explicação do abismo que surge com os movimentos vanguardistas e o público, ou entre a produção artística e a audiência, que tem como sinônimo a alienação entre a produção artística e o público. Vê-se assim que o entendimento adorniano da alienação (Entfremdung) comparece na década de 1920 sem conotação marxista ou materialista, funcionando como explicação para o abismo entre público e arte de vanguarda. Soma-se à ruptura entre o eu e as formas um processo específico à música, qual seja, o de gradual colapso da tonalidade, que se coloca em continuidade a Doutrina da harmonia de Schoenberg. Tal colapso da tonalidade é acompanhado de um questionamento da suposta natureza que tal sistema pretendia expressar: o advento da possibilidade de uma música dissonante expõe o artifício daquela tonalidade que se pressupunha como linguagem unívoca e absoluta da música - as dissonâncias não são como que exteriores à história da tonalidade, mas sim consequência de seu colapso, ou, nas palavras do próprio compositor, "são consequências naturais e lógicas de um organismo" (SCHOENBERG, 1985, p. 91). O que Schoenberg propõe, vale relembrar, é justamente uma compreensão da tonalidade que a conceitue como um princípio organizativo historicamente datado, revelando suas alterações internas e portanto seu caráter maleável e histórico, não natural: trata-se de negar a tonalidade enquanto linguagem expressiva de relações imutáveis, revelando sua segunda natureza, sua artificialidade enquanto linguagem supostamente natural. ${ }^{6}$

Somente com esses pressupostos é que conseguimos entender um pequeno, mas significativo texto-conversa de 1930 entre Adorno e seu amigo e compositor Ernst Krenek, chamado Problemas de trabalho dos compositores. Em certo sentido, esse texto pode ser visto como ponto culminante do pensamento de Adorno até então, na medida em que sintetiza um ponto essencial de seu diagnóstico estético, em conformidade com o que foi exposto acima: nas palavras de Adorno, "Para a consciência não há nenhum material puramente natural, mas sim um material histórico" (ADORNO, GS 19, p. 434). A isso se acrescenta que em Problemas de trabalho dos compositores há certa mudança de ênfase: como aponta Almeida, "Não se trata de uma 'conversa

época. A 'obrigatoriedade' das formas e tipos impostos por determinado estilo histórico submetia, assim, o artista individual e a obra singular a seu poder universalizante" (ALMEIDA, 2007, p. 33).

${ }^{5}$ Esse ponto é explicitado pelo próprio Adorno da seguinte maneira: "Todas elas [as formas tradicionais] perderam há muito tempo, na esfera da música absoluta, sua força criadora de vínculos. Sua objetividade interpessoal deixa de ser a portadora da música e a responsabilidade pelo que há de efetivo, também no âmbito musical, passa à pessoa, ao indivíduo" (ADORNO apud ALMEIDA, 2007, p. 139). As obras de Adorno serão citadas conforme os Gesammelte Schriften in 20 Bänden, na edição de 2003 da editora Suhrkamp, abreviada doravante por GS, seguida de indicação do volume e da respectiva paginação.

${ }^{6}$ Ver, a esse respeito, PADDISON, 1993, p. 71. 
sobre o conceito de material', mas sim de uma 'conversa sobre música e situação social'" (ALMEIDA, 2007, p. 289). Data de 1930, portanto, o movimento de Adorno em prol de um conceito amplo de sociedade, ou, dito de outro modo, a procura das articulações - das mediações - entre o material artístico e musical e a situação social.

Mas a inflexão decisiva ocorre, segundo nosso argumento, somente no ano seguinte de 1931, numa conferência concedida por Adorno chamada Por que é a nova arte de tão difícil compreensão? E sustentamos que o contato de Adorno com o marxismo se dá com a mediação de História e consciência de classe, livro de 1923 de Lukács. ${ }^{7}$ Aponta principalmente para essa mediação lukácsiana o fato de que, já nesse texto de 1931, a teoria marxiana da forma mercadoria venha sempre acompanhada do processo de autonomização das esferas de valor e, portanto, do processo de racionalização tal como descrito por Max Weber. Adorno repisa, nesse sentido, aquela síntese original de conceitos de Marx e de Weber promovida em História e consciência de classe. Se formos à conferência de 1931 - que anuncia já no primeiro parágrafo que se trata ali de uma investigação sociológica, não estética ${ }^{8}$, o que destarte indica uma mudança de abordagem em relação aos textos anteriores -, observaremos que a ênfase central não é a de realizar uma crítica de obras individuais, mas sim de explicar, em termos sociais, as razões que levaram à alienação reinante entre as obras da nova arte e o público. Adorno afirma:

A reificação [Verdinglichung] da arte é o resultado de um desenvolvimento socioeconômico que transforma todos os bens em mercadorias, fazendo-os abstratamente trocáveis, e portanto retirando-os da imediatez [Unmittelbarkeit] de uso. Aautonomia da arte, sua legalidade própria [Eigengesetzlichkeit], a impossibilidade de ordená-la à vontade de acordo com os ditames do uso, é, em contraste com a função cultual e cerimonial da prática artística passada, a expressão daquela reificação - reificação essa que entretanto aceitamos mais ou menos de coração tranquilo, mesmo onde as mercadorias conservam algo de seu valor de uso. Mas isto é profundamente preocupante e denuncia toda a situação na medida em que a possibilidade de uso desaparece por completo; e essa arte, em vez disso, deseja representar-se meramente como um relógio de sol em que numa face os homens pensam ver o estado geral de consciência, sem possuírem qualquer poder sobre o próprio estado geral de consciência. Descrever o advento dessa alienação [Entfremdung] seria nada menos que esboçar a história de nossa sociedade. (...) Tão pouco como pode uma sociedade altamente racionalizada reverter-se em uma sociedade natural, menos ainda podem seus produtos artísticos. (ADORNO, GS 18, p. 824, grifos meus)

É explícito que Adorno já opera aqui com o universo conceitual marxiano, do qual ainda não dispunha em 1930, em Problemas de trabalho dos compositores. Daí que aloquemos tal conferência de 1931 como o ponto de inflexão no pensamento

\footnotetext{
${ }^{7}$ Muito embora não tenhamos encontrado nenhuma referência precisa acerca da data em que Adorno leu História e consciência de classe, algumas outras indicações são relevantes nesse sentido: como primeiro ponto, é expressivo que Adorno afirme, em carta a Berg de 21 de junho de 1925, que Lukács foi um pensador que exerceu sobre ele uma influência como quase nenhum outro (ver ADORNO \& BERG, 2005, p. 9). Soma-se a isso que Adorno encontrou-se com Lukács também em 1925, como expõe numa carta a Kracauer, de 17/18 de junho do mesmo ano (ver ADORNO \& KRACAUER, 2008, pp. 79-80). Ademais, é significativo que Adorno discuta especificamente História e consciência de classe - mesmo que num contexto de explícita crítica à obra - em $A$ atualidade da filosofia, conferência de 1931 (ver ADORNO, GS 1, p. 337). O que significa que, até 1931, Adorno já havia lido a obra marxista de Lukács. Sobre a crítica de Adorno a Lukács em Aatualidade da filosofia, ver NOBRE, 1998, pp. 87-88. Paddison indica a centralidade de História e consciência de classe para o pensamento estético de Adorno: “De fato, à parte da jovem e pré-marxista Teoria do Romance, o trabalho de Lukács que provavelmente mais exerceu uma influência decisiva no jovem Adorno foi História e consciência de classe, um livro dificilmente preocupado com estética. A interpretação hegeliana de Marx que caracteriza esse trabalho, juntamente com o uso do conceito de 'racionalização' de Max Weber em sua discussão da burocracia e da tecnologia em relação à reificação na sociedade capitalista forneceu a Adorno poderosas ferramentas para aplicação ao campo estético" (PADDISON, 1993, p. 121). Ver também, sobre a importância de História e consciência de classe para o jovem Adorno, MARKUS, 2001, pp. 5-6.

${ }^{8}$ Adorno afirma: "ich frage soziologisch, nicht ästhetisch (...)" ["eu pergunto sociologicamente, não esteticamente"]. (Cf. ADORNO, GS 18, p. 824).
} 
sociológico-estético de Adorno, que marcaria como que o início de sua reflexão sobre sociologia musical. Mas tal operação com o universo marxista é feita, como atesta claramente a citação, juntamente com outro universo conceitual, de matriz weberiana, de sorte que Adorno, como já indicado, repisa a articulação promovida por Lukács entre essas duas matrizes conceituais diversas, mas o faz em um intuito particular, que é o de interpretar em chave materialista a arte de seu tempo.

Não queremos com tal afirmação dar a entender que Adorno simplesmente aceita, ao rearticular de maneira semelhante os universos conceituais marxiano e weberiano, a integralidade das teses e pressupostos de História e consciência de classe. Como diferença marcante, cumpriria ressaltar o ceticismo de Adorno em relação a um conceito positivo de totalidade. ${ }^{9}$ O próprio Adorno indica, em carta a Kracauer de 8 de junho de 1931, que buscava "conseguir um novo arranjo do materialismo" que prescindisse da categoria de "totalidade" ${ }^{10}$ Dessa distância em relação à noção de totalidade lukácsiana se segue que Adorno não enxergava no proletariado o sujeito social portador do ponto de vista da totalidade, o que já consistia num momento de revisão da Teoria crítica em relação às expectativas revolucionárias tal como delineadas por Lukács em 1923. Sobre essas questões, Olivier Voirol comenta que haveria em História e consciência de classe duas acepções do conceito de totalidade:

\begin{abstract}
Deve-se notar que o conceito de totalidade assume dois sentidos diferentes mas conectados em Lukács. De um lado como conceito político, ele implica uma concepção do sujeito social que é o portador do ponto de vista da totalidade: o proletariado, o operador mesmo da práxis que constitui o gênero humano naquilo que ele tem de genérico e universal; ele é o portador de uma totalidade desprezada que é chamado a recompor por sua ação política. Do outro lado, como conceito epistêmico, ele implica em assumir o ponto de vista da totalidade sobre o plano da teoria ao restituir uma visão do todo, contra o desenvolvimento capitalista que segmenta as realidades sociais, simultaneamente na prática e no conhecimento em proveito de uma divisão do trabalho crescente. Após o colapso das esperanças revolucionárias dos anos vinte e trinta e o "giro negativo" da Teoria Crítica nos anos quarenta, é ao conceito epistêmico que os autores frankfurtianos irão se referir essencialmente. (VOIROL, 2008, p. 57 , nota 12 , grifos do autor)
\end{abstract}

Seria portanto nesse segundo sentido epistêmico que Adorno se apropriaria do conceito lukácsiano de totalidade. Desse modo, a influência de Lukács sobre Adorno que aqui tentamos descrever refere-se estritamente ao intuito de reunir marxismo e weberianismo, de modo a interpretar a autonomia da arte e a racionalização do material e da sociedade como um todo enquanto processos entrelaçados à expansão da forma mercadoria e à reificação que acompanha tal expansão.

Retornando à citação de Adorno, de um lado, trata-se de considerar a obra de arte enquanto produto, isto é, enquanto artefato sujeito à forma mercadoria, porquanto trata-se de arte produzida na sociedade capitalista, na qual inexiste questão que não se reporte, direta ou indiretamente, à "solução do enigma da estrutura da mercadoria". ${ }^{11}$ Adorno considera, com Lukács, que a mercadoria se tornou "a forma universal de conformação da sociedade"12, interpretando a troca como médium universal a que tudo se conforma. A estrutura da mercadoria, tal como Lukács a descreve, seguindo os caminhos traçados por Marx no primeiro capítulo d'O Capital, estabelece que na moderna sociedade capitalista a produção destina-se especificamente à troca, impondo-se por isso uma abstração tanto do valor de uso quanto do trabalho concreto pelo qual

\footnotetext{
${ }^{9}$ Como é, aliás, atestado logo na primeira frase de sua conferência de 1931, A atualidade da filosofia. Ver ADORNO, GS 1 , p. 325

${ }^{10}$ Ver ADORNO \& KRACAUER, 2008, p. 283. A importância dessa carta foi indicada anteriormente por NOBRE, 1998, p. 61.

${ }^{11}$ Cf. LUKÁCS, 2012, p. 193.

${ }^{12}$ Cf. LUKÁCS, 2012, p. 196.
} 
se produz determinada mercadoria; tal abstração, necessária para a mensurabilidade das mercadorias destinadas à troca, termina por obliterar certos aspectos da própria mercadoria e de seu processo produtivo. ${ }^{13}$ Daí que se diga que a forma mercadoria opera uma mistificação, que transforma fatos sociais em fatos naturais, de sorte que o valor passe a aparecer como atributo natural da mercadoria, quando na verdade provém do trabalho humano e social.

Do outro lado, temos a constatação de que essa mesma sociedade capitalista passou por um processo de intensa racionalização, tomado aqui em sentido explicitamente weberiano, que por sua vez desembocaria no processo de autonomização das esferas de valor, esferas essas que constituem suas legalidades próprias (suas Eigengesetzlichkeiten). ${ }^{14}$ Essa autonomia da esfera artística significaria, segundo Weber, a emancipação da arte de qualquer motivo extra-artístico (na música, significaria que nada exterior ao próprio desenvolvimento do material deveria interferir no processo composicional), o que por sua vez apontaria para a emancipação, de um lado, da arte em relação ao bom e ao justo ${ }^{15}$, e, de outro, do próprio seio da sociedade na qual a arte é gerada, na medida mesma em que tal comunidade não mais se transmite, como ocorria nas comunidades com uma visão de mundo metafísica unificada, de maneira unívoca em todas as suas esferas.

Mas fica a questão: de que maneira pôde Lukács juntar em dobradiça duas vertentes essencialmente diversas de pensamento, como o marxismo e o weberianismo? ${ }^{16}$ É Habermas, em sua Teoria do agir comunicativo, que nos aponta a direção da resposta -o título do capítulo dedicado ao tema é, aliás, sugestivo: racionalização como reificação - ao afirmar que

Max Weber, como se demonstrou, buscou analogias estruturais subsistentes entre o agir formalmente racional da economia e da administração, entra as formas de organização da empresa capitalista e da burocracia pública, entre a concentração dos recursos empresariais em uma e outra, entre as orientações da ação próprias a empresários e funcionários públicos, trabalhadores horistas e de contrato fixo. Lukács, como dá a tenção a um único medium, o valor de troca, e como atribui a reificação tão somente à "abstração da troca", interpreta todos os fenômenos do racionalismo ocidental como sinais do "processo de ocupação plena de toda sociedade pelo capital". Em face do caráter abrangente da racionalização social diagnosticada por Weber, Lukács entende que ele confirma sua própria assunção de que a forma mercadoria se impõe como forma de objetualidade dominante na sociedade capitalista (...). (HABERMAS, 2012, p. 619 , grifo meu)

Com efeito, no "caráter abrangente da racionalização" e no multifacetado processo de autonomização das esferas de valor, Lukács enxerga na verdade um único processo maior, que é aquele da expansão da forma mercadoria. Tal expansão implica, como já explicitado, o fato de que a mercadoria se torna, no capitalismo, “a forma universal de conformação da sociedade". Em outras palavras, a pluralidade de significados da modernização weberiana é aglutinada sob um único prisma, que é a universalidade da forma mercadoria, e da reificação que a acompanha. Soma-se a isso que, como se sabe, para Lukács o que diferencia a teoria marxista das outras teorias "tradicionais" ou "burguesas" - da qual a teoria weberiana faria parte - é

\footnotetext{
${ }^{13}$ Cf. LUKÁCS, 2012, p. 200.

${ }^{14}$ A relação entre os dois processos (de racionalização e de autonomização das esferas de valor) é motivo de amplo debate entre os comentadores de Weber, tema que não abordaremos em detalhe. A esse respeito, ver, por exemplo, WAIZBORT, 1995, p. 28.

${ }^{15}$ Como afirmado em WEBER, 2011, p. 50.

${ }^{16}$ É evidente que a pergunta suscita uma série de questões, especialmente no que se refere à relação entre a teoria marxista com a teoria tradicional; sobre isso, cf. o interessante artigo de Teixeira (2014), no qual ela afirma: “A contraposição entre o que Lukács chama de 'ciência burguesa' e 'ponto de vista do proletariado' pode ser considerada o protótipo daquela entre teoria crítica e teoria tradicional, desenvolvida posteriormente por Horkheimer" (TEIXEIRA, 2014, p. 7).
} 
o ponto de vista da totalidade: precisamente por essa concepção de totalidade abarcar o falso como momento do verdadeiro é que se torna possível se aproveitar de conceitos e processos não-marxistas. ${ }^{17}$ A proeza e a dificuldade do materialismo estético nascente de Adorno será a tentativa de manter esse arranjo entre marxismo e weberianismo prescindindo de uma concepção forte e política da categoria de totalidade, de maneira a alterar o esquema luckásciano. ${ }^{18}$

Ainda no bojo desse raciocínio está outro movimento sutil da argumentação adorniana, que marca uma diferença em relação à década de 1920: a temática da ruptura entre o eu e as formas é reposta, mas em chave sociológica e materialista. De um lado, temos uma argumentação que salienta o fetichismo da mercadoria:

Quando se fala da autoconsciente especialização dos artistas modernos, ou quando, filistinamente, se aposta contra o ideal do l'art pour l'art (...), se quer dizer nada diverso do que aquela alienação [Entfremdung] entre produção e consumo, do que aquela radical e integral reificação de toda arte, que a retira da imediatez de uso e destarte de sua compreensibilidade [Verständlichkeit] imediata. (ADORNO, GS 18, p. 825)

Observa-se assim que há uma concomitância entre a perda da função do uso, decorrente daquela abstração da forma mercadoria que padroniza inclusive os produtos artísticos para a troca, e a consequente ausência de imediatez de compreensão por parte do público. Do outro lado, Adorno indica que também a racionalização do material artístico e a autonomização da esfera da arte são centrais para a explicação da ruptura da imediatez de compreensibilidade da nova arte:

Porque a dado momento a arte rompeu os grilhões do uso imediato, inserem-se nela inevitavelmente certos desenvolvimentos [Entwicklungen] - desenvolvimentos sociais inclusive -, sem eles próprios estarem em conexão com a atual consciência heterônoma da sociedade. Semelhantemente, o desenvolvimento [Entwicklung] da matemática pode ter sido, a dado momento, produzido pela autonomia burguesa, pelas ciências naturais técnicas; e, apesar disso, justamente em função do princípio da autonomia, tal desenvolvimento termina por separa-se ainda mais da compreensão social, tornando-se ainda mais "especial". Essa dialética é o verdadeiro fundamento da irreversibilidade das dificuldades artísticas. (ADORNO, GS 18, p. 828)

Atrela-se aqui a perda da imediatez da compreensão social da arte ao processo de autonomização da esfera artística, que Adorno interpreta de maneira peculiar: como nos faz notar Peter Bürger, é primordial apontar para “(...) a contrariedade da categoria de autonomia: necessária para a definição do que a arte é na sociedade burguesa, ela traz em si, ao mesmo tempo, a mácula da deformação ideológica, na medida em que não permite reconhecer sua condicionalidade social" (BÜRGER, 2012, p. 73). O paradoxo é o de que a mesma racionalização "reificante" que constituiu a arte de vanguarda agora a isola do todo social, e tal isolamento se expressa precisamente na perda da compreensibilidade imediata das obras - donde surge a insistente

\footnotetext{
${ }^{17}$ Como afirma Lukács logo no prefácio de História e consciência de classe: “Na pura historização [Geschichtlichwerden] da dialética, essa constatação se dialetiza mais uma vez: o 'falso' é, ao mesmo tempo, um momento do 'verdadeiro' enquanto 'falso' e enquanto 'não-falso'" (LUKÁCS, 2012, p. 60). Se seguirmos o artigo de Teixeira, temos que: "Para Lukács, portanto, superar a parcialidade de uma teoria significa considerá-la como um momento da totalidade e, assim, conferir a ela um novo significado nesse contexto do movimento total. Esse posicionamento pode ser comprovado, por exemplo, no uso que é feito em História e consciência de classe de determinadas ideias de autores citados anteriormente, especialmente Weber e Simmel (...)" (TEIXEIRA, 2014, p. 10).

${ }^{18}$ A longevidade da noção explicativa - mas não política - de totalidade na sociologia musical adorniana pode ser encontrada, por exemplo, num ensaio de 1959 chamado Ideias para a sociologia da música: "O conceito essencial da sociedade (Inbegriff der Gesellschaft), entretanto, que não só abarca todas as chamadas áreas parciais, mas comparece por inteiro em cada uma delas, não é um campo de fatos mais ou menos interligados, nem é uma classe lógica suprema, à qual se pudesse chegar pela progressiva generalização. Ele é em si mesmo um processo, um nexo que se produz e produz os seus momentos parciais, uma totalidade no sentido de Hegel" (ADORNO, 1983, p. 259).
} 
afirmação de Adorno que o choque é a característica básica de toda a nova arte, indício da existência de uma alienação entre a Nova arte e o público. ${ }^{19}$ Mas tal isolamento nunca é completo, visto que seu material artístico e musical possui inerentemente um conteúdo social; daí que Bürger ressalte a "condicionalidade social" que perpassa a concepção adorniana de autonomia da arte.

À tal articulação se acrescenta ainda o processo de ruptura entre a esfera da produção musical em relação à esfera de seu consumo: a descontinuidade entre produção e consumo virá como outro elemento explicativo da perda da compreensibilidade imediata das obras de arte, que caracteriza o choque causado pelo vanguardismo na audiência. É o que Adorno indicará ainda na conferência de 1931:

Mas a arte que se baseia na realidade dada reivindicando a compreensibilidade geral e a equivalência social necessariamente possui uma função ideológica, conciliadora. (...) É certo que a produção comporta-se de maneira histórico-dialética, na medida em que exprime as tensões e contradições das relações existentes (...). O consumo, todavia, persiste de maneira imóvel, pois não lhe é próprio a força de produção [Produktivkraft] que apontaria para além de sua imobilidade; o consumo é apenas socialmente produzido, sem ser por si mesmo produtivo - ao mínimo no campo estético - e espelha somente certas relações que têm como necessidade primeira a manutenção delas mesmas. A dificuldade de entendimento da nova arte possui seu motivo específico nessa necessária autorreferência [Rückbezogenheit] da consciência de consumo a uma situação espiritual e social em que toda saída acerca em relação ao imediatamente dado [Gegebenheiten], toda descoberta de sua contradição, configura uma ameaça. (ADORNO, GS 18, p. 828)

O que Adorno aponta aqui é um hiato entre as esferas de produção e de consumo, a primeira ainda expressando um momento de resistência e certa dinâmica interna, a segunda capitulando inteiramente ao status quo da sociedade reificada e, portanto, recalcitrante frente à uma parcela da própria produção artística. O "motivo específico" que caracteriza a dificuldade de compreensão da nova música e da nova arte é o fato de que essa arte é produzida nos poucos locais em que o imperativo do consumo ainda não eliminou aquele caráter "histórico-dialético" que caracteriza a produção. É essa resistência da esfera produtiva, juntamente com o caráter autônomo da esfera artística, que permite à nova arte simultaneamente espelhar e rejeitar as relações sociais existentes em seu material, não reproduzindo as relações heterônomas sem mais. ${ }^{20}$ Daí que escreva Paddison:

Adorno enxerga a totalidade social como fraturada e contraditória, feita de antagonismos. A música, em seus próprios termos (isto é, em seu material e estuturas), 'delineia nas mais

\footnotetext{
${ }^{19}$ Sabe-se que Adorno, num texto da década de 1960, rejeitou vigorosamente esse raciocínio: “As explicações quanto à desproporção entre a nova música e sua compreensão são até agora insatisfatórias. Nisso incluo trabalhos meus sobre esse mesmo assunto, como aqueles que publiquei, antes de 1933, sob o título 'Por que é a nova arte de tão difícil compreensão?'. Em geral acaba aparecendo aí a palavra-chave 'alienação'. Associa-se a isso que, mais ou menos a partir da metade do século XIX, a progressiva autonomia da arte a teria afastado cada vez mais dos homens; o abismo que, na lírica, existe entre Heine e Baudelaire. Ele também percorre a música; em geral, Tristão é considerado o seu momento. Essa tese, entrementes já transformada em clichê, usa, para esclarecer a situação fática, a constatação dela. Caso se retire da argumentação todo o enfeite e toda a tralha da erudição, então o que resta é que os homens estariam distanciados e alienados em relação à nova música porque estão distanciados e alienados em relação a ela" (ADORNO, 1994, p. 148, tradução modificada). Não se trata aqui de apontar a longevidade desse modelo específico de sociologia musical no pensamento adorniano a longo prazo, mas sim de tentar mostrar de que maneira Adorno o formula, de sorte que se evidencie como esses primeiros escritos informaram decisivamente sua sociologia musical como um todo, inclusive a tardia da década de 1960.

${ }^{20}$ Ora, não é precisamente esse caráter de resistência da produção frente aos imperativos do mercado que irá se perder quando do diagnóstico da indústria cultural? "Por enquanto, a técnica da indústria cultural levou apenas à padronização e à produção em série, sacrificando o que fazia a diferença entre a lógica da obra e a do sistema social" (ADORNO \& HORKHEIMER, 2006, p. 100). Essa indistinção entre a lógica da obra e a lógica do mercado, que suprime a possibilidade histórico-dialética da produção tal como caracterizada nos anos 1931-1932, é uma das características fundamentais do diagnóstico encontrado na Dialética do Esclarecimento e da década de 1940 como um todo.
} 
evidentes linhas as contradições e fraturas que permeiam a sociedade atual'. E todavia a música autônoma, desde o início do período período burguês, foi apartada e separada da sociedade por essas mesmas contradições e 'fraturas' (por exemplo, a divisão do trabalho) que ela re-presenta em seu próprio material. Sua autonomia permitiu à música a desenvolver-se em paralelo à sociedade, espelhando seus antagonismos, e simultaneamente divergindo dela, desenvolvendo uma dinâmica própria. Muito embora a música seja autonoma e separada da sociedade, ela apesar disso contém a sociedade 'sedimentada' em seu material; isso costitui seu caráter social ou 'substância' (Gehalt). (PADDISON, 1993, p. 98)

Ora, não é este raciocínio explicitamente contrário a certas correntes do marxismo ortodoxo, que concebem as produções artísticas como meras manifestações de uma superestrutura econômica, sorvendo a produção artística num esquema de compreensão do que seja a sociedade capitalista? O ponto é o de que nesse arranjo proposto por Adorno, em que a música, em função da autonomia da qual goza, mediatamente espelha e reproduz as relações sociais em seu material, se evidencia uma divergência de princípio com aquilo que Adorno denominava "marxismo vulgar": nas palavras de Paddison, Adorno "(...) rejeita o determinismo socioeconômico bruto em sua interpretação de Marx" pois seu argumento vai no sentido de expressar que "a arte não somente reflete a sociedade mas também se opõe a ela, que não somente ela converge com a sociedade mas também diverge dela e desenvolve sua dinâmica própria (...)" (PADDISON, 1993, p. 128).

Passando ao texto de 1932 de Adorno, chamado Sobre a situação social da música, publicado na Zeitschirft für Sozialforschung, a revista do Instituto de pesquisa social, vemos ali uma reafirmação contundente do diagnóstico elaborado em 1931, em Por que é a nova arte de tão difícil compreensão? Logo no primeiro parágrafo repete-se o mesmo arcabouço argumentativo apresentado no ano anterior. Em primeiro lugar, trata-se de constatar o efeito da expansão da forma mercadoria e suas respectivas consequências para o âmbito musical:

O papel da música no processo social é exclusivamente aquele de uma mercadoria; seu valor é determinado pelo mercado. Ela não mais serve às necessidades e usos imediatos, mas ajusta-se com todos os outros bens às pressões de trocas de unidades abstratas. Seu valor de uso - se é que ele ainda existe - subordina-se também às pressões de troca. As ilhas de produção pré-capitalista do "fazer musical", como as que o século XIX ainda podia permitir, foram exterminadas [überspült] (...). (ADORNO, GS 18, p. 729)

Trata-se assim de atrelar a perda de toda imediatez de compreensão ao próprio desenvolvimento capitalista, de sorte que a expansão da forma mercadoria, na medida em que oblitera o valor de uso em função da abstração necessária à troca, fornece um primeiro elemento explicativo para a compreensão da alienação que atinge o público. Aliado a isso está o próprio processo de racionalização, que, ao forjar uma esfera própria à arte, retira da música sua comunicabilidade imediata, isolando-a do todo social - isolamento que nunca é completo, pois, como vimos, esse mesmo todo social está sedimentado, mediatamente, no material musical. A esses dois processos soma-se ainda um terceiro: a absorção tanto da esfera da produção quanto da esfera do consumo pelo processo capitalista coopera com o processo de alienação, na medida em que limita, de um lado, a própria esfera da produção, que deve subordinar-se aos ditames do mercado, e de outro o público, que se torna incapaz de absorver as obras de certos setores da produção artística que não se submetem integralmente às exigências do consumo.

Mas o ponto mais relevante para nosso argumento está na ênfase concedida à intrincada relação entre produção e consumo, que nesse texto de 1932 consistirá na base mesma da crítica estética que Adorno promove. Em outras palavras, tal relação entre produção e consumo servirá tanto para explicar a alienação entre música e sociedade, quanto para avaliar as diversas vanguardas sob a perspectiva da reação ou do progresso. Em 1932, portanto, não é só a posição do compositor em relação ao 
material musical que irá definir o campo em que ele se encontra, mas também sua própria posição frente às exigências do mercado. Dois dados estruturais do texto revelam tal centralidade: em primeiro lugar, o ensaio é dividido em duas partes (produção; consumo). Em segundo, é válido apontar que, na primeira parte do texto, dedicada à esfera da produção, temos, grosso modo, duas partes internas - uma primeira, funcionando como um diagnóstico geral da atual situação social da música, e uma segunda, na qual Adorno passa em revista diversos compositores, como Schoenberg, Stravinsky, Hindemith, Bártok, entre outros. Ora, é justamente esse diagnóstico geral que antecede as considerações sobre os diversos líderes de vanguardas que revela a chave na qual esses artistas serão interpretados, de sorte que é a própria posição de determinada vanguarda no interior da relação entre produção e consumo que determinará sua posição ou bem como progressiva, ou bem como regressiva:

De um ponto de vista social, a atividade musical contemporânea - produção e consumo pode ser drasticamente dividida em aquela que incondicionalmente reconhece seu caráter de mercadoria [Warencharakter] e, ao recusar qualquer intervenção dialética, orienta-se segundo as demandas do mercado, e aquela que em princípio não se orienta pelo mercado. Dito de outra maneira: no interior da alienação da sociedade e da música, o primeiro grupo - passiva e não-dialeticamente - toma o lado da sociedade, enquanto o segundo toma o lado da música. (ADORNO, GS 18, p. 733)

Adorno passa então a desenvolver uma "tipologia musical" baseada nessa distinção entre música de mercado e música de vanguarda: a primeira reproduzindo a sociedade capitalista positiva e afirmando seu caráter de mercadoria, e a segunda, que pretende, de variadas maneiras, negar tanto a heteronomia social quanto as imposições do mercado. Vale atentar que não é o caso que a música que nega sua submissão ao mercado rejeite a própria alienação que a afeta - antes, ela a expressa: ao não negar artificialmente a alienação que a atinge e ao adotar o caráter histórico do desenvolvimento do material, tal música expõe, para falar com Adorno, as próprias "rachaduras" da presente sociedade.

E também em Sobre a situação da música Adorno faz ver sua crítica ao marxismo vulgar, quando afirma:

Se se estabelece o desenvolvimento imanente da música de maneira absoluta - como mero reflexo dos processos sociais - então se sanciona o caráter de fetiche da música, que é justamente o maior problema e dificuldade a ser representado por ela própria. De outro lado, é evidente que a música não deve ser medida pela sociedade existente, que simultaneamente a produz e a isola. É assim pressuposto de todo método histórico-materialista, que espera ser mais que "histórico-espiritual", que sob nenhuma condição a música deva ser apreendida como fenômeno "espiritual", de maneira abstrata e distanciada das relações sociais de fato (...). (ADORNO, GS 18, p. 731)

Conseguimos assim delimitar com maior precisão a concepção heterodoxa de materialismo que Adorno desenvolve ao início da década de 1930: como já afirmamos, trata-se sempre de negar uma estética "histórico-espiritual", que absolutiza a condição de autonomia da arte, tratando-a como um fenômeno puramente espiritual e apartado das relações sociais. ${ }^{21}$ Do outro lado, Adorno insiste em não reduzir completamente o fenômeno artístico às próprias relações sociais, porquanto isso significaria que a obra de arte meramente refletiria a heteronomia da própria sociedade capitalista na qual está inserida - se assim fosse, as obras sancionariam a ideologia tout court. $\mathrm{O}$ caminho intermediário encontrado por Adorno é sua teoria da mediação, que tem como locus, ao menos nos textos do início da década de 1930, o material musical, e que funciona para aquilatar uma concepção própria de materialismo.

\footnotetext{
${ }^{21}$ Ver PADDISON, 1993, pp. 99-100.
} 
Em suma, pretendemos ter mostrado, em nossa reconstrução desses dois textos de Adorno do início dos anos 30, que ali se esboça uma primeira concepção de materialismo estético muito própria: o que pudemos notar foi que Adorno pensa os mesmos problemas da década de 1920 (perda da Verbindlichkeit, alienação entre vanguarda e público, etc.) em um universo conceitual expressamente materialista. $\mathrm{O}$ fato de que a expansão da forma mercadoria sempre compareça nesses textos aliada tanto ao fenômeno do fetichismo quanto à racionalização ocidental e à autonomia da esfera artística indica, segundo nosso argumento, que Adorno, nesses primeiros escritos de sociologia da música, apropriou-se da articulação entre conceitos weberianos e marxianos promovida por Lukács em História e consciência de classe. E é a partir dessa apropriação específica que Adorno teve do marxismo, logo ao início da década de 1930, que poderíamos abordar as futuras divergências entre Adorno e Benjamin em sua Correspondência, divergências essas que, em parte, giram em torno da compreensão diversa que os autores nutriam sobre o materialismo, uma vez que tiveram relações e apropriações diversas em torno do marxismo. O que, todavia, é assunto para outro trabalho.

Correspondência: Lutti Mira. Universidade de São Paulo - USP. Faculdade de Filosofia, Letras e Ciências Humanas. Departamento de Filosofia. Av. Prof. Luciano Gualberto, 315, Sala 1007, Conjunto Didático de Filosofia e Ciências Sociais. Cidade Universitária. São Paulo - SP - Brasil. CEP 05508-010. E-mail: luttimira@ gmail.com.

Apoio financeiro: FAPESP

Conflito de interesses: Nenhum.

Todos os autores leram e aprovam a versão final submetida à revista Em curso. 


\section{Referências bibliográficas:}

ADORNO, T. W. Gesammelte Schriften in 20 Bänden (GS). Frankfurt am Main: Suhrkamp, 2003. . Ideias para a sociologia da música. In: BENJAMIN, W.; ADORNO, T. W.;HORKHEIMER, M.; HABERMAS, J. Textos escolhidos. São Paulo: Abril Cultural, 1983. Ática, 1994. Por que é difícil a nova música. In: COGN, G. (Org.). Theodor W. Adorno: Sociologia. São Paulo: ; HORKHEIMER, M. Dialética do esclarecimento: Fragmentos filosóficos. Rio de Janeiro: Zahar, 2006. ; KRACAUER, S. Briefwechsel 1923-1966. Frankfurt am Main: Suhrkamp, 2008. ; BERG, A. Correspondence 1925-1935. Polity Press, 2005.

AGAMBEN, G. O príncipe e o sapo: O problema do método em Adorno e Benjamin. In: Infância e história: Destruição da experiência e origem da história. Belo Horizonte: Editora UFMG, 2005, p. 127-147.

ALMEIDA, J. Crítica dialética em Theodor Adorno: Música e verdade nos anos vinte. Cotia: Ateliê Editorial, 2007.

BÜRGER, P. Teoria da vanguarda. São Paulo: Cosac Naify, 2012.

HABERMAS, J. Teoria do agir comunicativo. Tomo 1: Racionalidade da ação e racionalização social. São Paulo: Martins Fontes, 2012.

LUKÁCS, G. História e consciência de classe: Estudos sobre a dialética marxista. São Paulo: Martins Fontes, 2012. MARKUS, G. Walter Benjamin or: The commodity as phantasmagoria. New German Critique, no. 83, p. 3-42, 2001.

NOBRE, M. A dialética negativa de Theodor W. Adorno: A ontologia do estado falso. São Paulo: Iluminuras, 1998.

PADDISON, M. Adorno's aesthetics of music. Cambridge: Cambridge University Press, 1993.

PETAZZI, C. Th. Wiesengrund Adorno: Linee di origine e di sviluppo del pensiero. Firenze: La nuova Italia, 1975. SCHOENBERG, A. Style and idea. Berkeley: University of California Press, 1985.

TEIXEIRA, M. O. N. Modelos críticos e teoria social tradicional: A dialética entre pesquisa e apresentação em Georg Lukács e Max Horkheimer. Revista Limiar, São Paulo, n. 2, p. 30-106, 2014.

VOIROL, O. Médiations et théorie critique. Questions et actualité d'un projet sociologique. Revue Réseaux, n. 148-149, p. 47-78, 2008/2.

WAIZBORT, L. Introdução. In: WEBER, M. Os fundamentos racionais e sociológicos da música. São Paulo: EDUSP, 1995, p. 23-52.

WEBER, M. Ciência e política: Duas vocações. São Paulo: Cultrix, 2011.

Recebido em: 08/Mai/2018 - Aceito em: 06/Ago/2018. 